\title{
Effect of Short-Term Swim Exercise on Cardiac Dysfunction Induced by Doxorubicin in Rats
}

\author{
FATEN M.A. DIAB, M.D.*; RAMADAN A. SAAD, M.D.****; NOHA A. NASSEF, M.D.* and \\ CHRISTINA M. WADIE, M.Sc.* \\ The Department of Physiology*, Faculty of Medicine, Ain Shams University, Cairo, Egypt* and \\ Fakeeh College of Medical Sciences, KSA**
}

\begin{abstract}
Background: Long-term exercise could confer protection against Doxorubicin-induced cardiotoxicity, yet, the effect of short-term exercise just prior to exposure to Doxorubicin (Dox) is still unclear.

Aim: To investigate the effect of short-term exercise on cardiac dysfunction induced by Dox treatment.

Material and Methods: Sixty nine female albino rats were assigned into 4 groups: Group 1: Control (sedentary rats, $\mathrm{n}=17$ ), Group 2: Dox (rats received single intraperitoneal injection of Dox in a dose of $20 \mathrm{mg} / \mathrm{kg}, \mathrm{n}=18$ ), Group 3: Exc, $(n=16)$, Group 4: Exc + Dox $(n=18)$. Rats were subjected to recording of the ECG, measurement of arterial blood pressure, echocardiograghy, analysis of serum parameters of SGOT, $\mathrm{LDH}, \mathrm{CPK}-\mathrm{MB}$, troponin I (cTnI) and evaluation of tota antioxidant capacity, Malondialdehyde (MDA) and heat shock protein (Hsp20) in the cardiac tissue.
\end{abstract}

Results: Compared to the control, Dox-treated rats showed significant prolongation of QT interval, with insignificant depression of the $\mathrm{R}$ voltage and the elevation of systolic (SBP), diastolic (DBP), mean (MAP) blood pressures were statistically insignificant. These changes were accompanied by significant elevation of serum SGOT and cardiac tissue MDA and Hsp20. Also, compared to the control, rats exposed to 3 days exercise just before Dox injection (Exc + Dox) showed significant prolongation of QT even more than in Dox group. However, the depression of the $\mathrm{R}$ voltage and the elevation of the SBP, DBP, and MAP become statistically significant compared to the control. These changes were associated with significant increase in SGOT. However, compared to Dox group, the Exc+Dox demonstrated significant prolongation in QT, significant reduction in the ejection fraction with significant reductions in MDA and Hsp20.

Conclusion: Short-term swim exercise training just prior to doxorubicin exposure is risky and makes the heart more predisposed to arrhythmia despite of the relative improvement in cardiac oxidative status.

Key Words: Doxorubicin - Cardiac dysfunction - Exercise Hsp20.

Correspondence to: Dr. Noha A. Nassef, E-Mail: nohanassef@med.asu.edu.eg

\section{Introduction}

DOXORUBICIN, quinine containing anthracycline antibiotic, is one of the most frequently used chemotherapeutic drug against most of solid tumors and hematological malignancies [1]. Unfortunately, the clinical use of this valuable drug is limited due to its dose-dependent life-threatening side effects especially on the heart [2] . In this regard, it had been reported that Doxorubicin (Dox) stimulates Reactive Oxygen Species (ROS) generation by the mitochondria that leads to generation of a free radical cascade with potent oxidizing power [3] Regrettably, the level of Dox-induced oxidative stress on the heart is up to 10 times greater than other tissues as the liver or the kidney, because the heart exhibit low level of antioxidant enzymes which detoxifies the $\mathrm{H}_{2} \mathrm{O}_{2}[4]$ thus, the oxidative injury of the heart is the widely accepted theory presumed as a primary mechanism of Dox-induced cardiotoxicity $[\mathbf{5}]$.

Numerous techniques have been employed in an attempt to decrease the Dox-induced cardiotoxicity, either by minimizing the amount of drug administered while retaining its anti-tumor efficacy [6]; providing long-term drug exposure but at modest concentration [7]; applying a drug delivery system such as liposomes and nanoparticles [8]; and combating the Dox administration with a cardioprotective drug that improves oxidant defenses of the cardiomyocytes like melatonin [9] and vitamin D [10]. Yet, most of the previously mentioned techniques have had limited success and the Dox cardiotoxicity remains a major problem.

Long-term exercise training for 10 weeks or 8 weeks could confer protection against doxorubicin cardiotoxicity $[11,12]$. However, this protective tool 
has a limiting factor on clinical application, as many individuals are not physically active or already having sedentary life style, in addition to, the short duration period intervening the diagnosis of cancer and the start of its management whether by surgical and/or Dox treatment. From this point of view and for clinical applicability, the shortterm exercise training immediately before Dox administration might develop a great concern.

\section{Material and Methods}

Ethical approval: All rats received care in accordance with the National Health Guidelines and the study protocol was approved by the Research Ethical Committee of Faculty of Medicine Ain Shams University.

Chemicals: Doxorubicin was purchased from regular pharmacy, dissolved in saline and injected immediately after its preparation.

Experimental animals: This study was carried out on 69 female local strain albino rats weighing 180-260 grams. Rats were purchased from an experimental animal farm (Fisal, Giza) and maintained in the Physiology Department Animal House. The study was conducted in the period from 20152017. Rats were kept under standard conditions of boarding at room temperature $\left(22-28^{\circ} \mathrm{C}\right)$ with normal light dark cycle. Rats were fed the regular meals of standard rat chow diet with free access to water. Rats were kept for 3 days for acclimatization before starting the experiment. Rats were initially weighed (iBW) and randomly assigned into 4 groups:

Group 1: Control group (control) $(\mathrm{n}=17)$ : Rats in this group were kept sedentary and received single intraperitoneal (i.p) saline injection as a placebo and were studied 24 hours later.

Group 2: Doxorubicin-treated group (Dox) $(n=18)$ : Rats in this group were kept sedentary, like Group 1, but received single intraperitoneal injection of doxorubicin in a dose of $20 \mathrm{mg} / \mathrm{kg}$ body weight [13] and were also studied 24 hours later.

Group 3: Swim-exercised group (Exc) $(\mathrm{n}=16)$ : Rats in this group were exposed to short-term swim training exercise ( 1 hour/day for 3 days) and on the last day of exercise, rats received ip injection of saline and studied 24 hours later.

Group 4: Swim-exercised, doxorubicin-treated group (Exc + Dox $)(n=18)$ : Rats in this group were exposed to the same exercise program as Group 3 , and on the last day of exercise, rats received ip injection of Dox using the same dose as in Group 2 and were studied 24 hours later.
Exercise training program: Exercised rat groups were exposed to a swimming exercise in the animal swimming pool apparatus $(100 \mathrm{~cm}$ length, $70 \mathrm{~cm}$ width and $70 \mathrm{~cm}$ depth) in our department. This apparatus was filled with thermally maintained water $\left(31^{\circ} \mathrm{C} \pm 1\right)$ to a depth of $50 \mathrm{~cm}$. The apparatus is provided with a strong fan (1425 revolutions per minute) that gives strong water currents which help to ensure uniformity of temperature. During the exercise swim sessions, the rats (average 4 to 6 rats) were placed in the pool and were continuously monitored and forced to be active all the 1 hour period of the swim session.

Experimental procedures: On the day of sacrifice, over night fasted rats, except for free access to water, were taken from their home cages and subjected to arterial blood pressure measurement. Then, rats were weighed (final body weight, fBW) and anesthetized by intraperitoneal injection of sodium pentobarbital $(25 \mathrm{mg} / \mathrm{kg})$ [14] and subjected to Echocardiographic (Echo) and Electrocardiographic (EGG) recordings. The dose was chosen after some trials that finally adjusted the dose of anesthesia in such a level that allows for performing the procedures without inducing bradycardia that may affect the systolic function assessed by Echo. After that, each rat was subjected to a midline abdominal incision. The abdominal aorta was exposed and cannulated with a catheter and blood samples were collected in a plastic centrifuge tubes. Then, a mid thoracic incision was done, heart was excised, washed by cold saline and dried by filter paper. Atria (AT), Right Ventricle (RV) and Left Ventricle (LV) were dissected, weighed in 5-digitmetler balance (AE 163) and the LV of each rat was cut into 3 pieces. Each piece was weight and stored in aliquot at $-80^{\circ} \mathrm{C}$ for later determination of Malondialdehyde (MDA), total antioxidant capacity (T.antioxidant) and heat shock protein (Hsp20). The weights of the AT, RV, LV and Whole Heart (WH) were expressed as absolute values (mg) as well as relative values (cardiac indices) as absolute weight/body weight ratios $(\mathrm{mg} / \mathrm{g})$. The blood samples that were collected from aorta, left to clot and were centrifuged at 3000rpm for 15 minutes for serum separation. The serum was pipetted off and kept in aliquots at $80^{\circ} \mathrm{C}$ for determination of Serum Glutamic-Oxaloacetic Transaminase (SGOT), cardiac troponin I (cTnI), Lactate Dehydrogenase (LDH), cardiac creatine phosphokinase (CPK-MB).

A- Measurement of rat tail arterial blood pressure: In conscious rats, Systolic Blood Pressure (SBP), Diastolic Blood Pressure (DBP) and Mean arterial Blood Pressure (MBP) were meas- 
ured simultaneously with the Heart Rate (sHR) using non invasive small animal tail blood pressure system, which is an electronic version of traditional sphygmomanometer cuff method (NIBP 200A, Biopac systems Inc.; USA).

B- Echocardiographic evaluation (Echo):Transthoracic echocardiographic evaluation was performed using Vivid 7 Dimension, GE (Vingmed ultrasound AS N-3190 Horten, Norway). The echocardiographer was blinded with respect to the treatment and control groups. Left ventricular systolic function was determined by estimation of Ejection Fraction (EF) and Fraction of Shortening (FS) [15]. The previous mentioned dose of sodium pentobarbital $(25 \mathrm{mg} / \mathrm{kg})$ was used as a sedative and a prewarmed ultrasound transmission gel (Parker Laboratory, Orange, NJ) was applied to the precordium. Ejection fraction was calculated from the left ventricle cross-sectional area (2-D short-axis view) using the equation:

$$
\text { Ejection fraction }(\%)=\frac{(\text { LVDA }- \text { LVSA })}{\text { LVDA }} \times 100
$$

Fraction of shortening was calculated from the M-mode LV dimensions using the equation: Fraction of shortening $(\%)=[(\mathrm{LVEDD}-\mathrm{LVESD}) /$ LVEDD] X 100 where LVEDD stands for LV enddiastolic internal diameter and LVESD stands for LV end-systolic internal diameter.

$C$ - Electrocardiographic recording (ECG): In anesthetized rats, the electrocardiograph tracing (from lead II) was recorded using standard limb leads. Needle electrodes were placed under the skin of the four limbs of the animal near the paws and connected through an ECG recorder (Cardimax FX-2111, Fukuda Denishi Co., Ltd., Japan). Heart rate was calculated, from the ECG, using the following formula: HR (bpm) $=3000 /$ distance in $\mathrm{mm}$ between 2 successive peaks of $\mathrm{R}$ waves.

Also, the voltage of $\mathrm{R}$ wave ( of PR and QT interval ( $\mathrm{msec})$ were measured and corrected QT (QT-c) was calculated as follows:

$$
\text { QT- }{ }_{C}=\text { observed QT }\left(\mathrm{QT}_{-}{ }_{\mathrm{o}}\right) / \sqrt{ } \mathrm{R}-\mathrm{R} \text { in seconds [16] }
$$

$D$ - Biochemical analysis: All the tests were performed by technicians who were blinded regarding the different rat groups.

Tissue homogenization: First of all, the tissue samples were homogenized by adding phosphate buffer solution ( $\mathrm{pH}$ 7.4). Then, the supernatants were carefully collected after centrifugation for $20 \mathrm{~min}$ at $3000 \mathrm{rpm}$.

1- Cardiac tissue malondialdehyde (MDA) was determined according to Ohkawa et al., [17] using kits supplied by Biodiagnostic.

2- Cardiac tissue total antioxidant capacity was determined according to Koracevic et al., [18] using kits supplied by Biodiagnostic.

3- Cardiac tissue heat shock protein (Hsp 20) was determined by mico ELISA technique using kits supplied by Sunlong biotech Co., LTD.

4- Serum Glutamic-Oxaloacetic Transaminase (SGOT) was estimated according to the colorimetric method described by Reitman and Frankel [19] using kits supplied by Biodiagnostic.

5- Cardiac tissue troponin I (cTnI) was determined according to Apple et al., [20] using kits supplied by Immunospeccorporation.

6- Lactate Dehydrogenase (LDH) was determined according to Bulh and Jackson [21] using kits supplied by Stanbio Laboratory.

7- Cardiac Creatinephosphokinse (CPK-MB) was determined according to Tholen et al., [22] using kits supplied by Beckman Coulter.

\section{Statistical analysis:}

Statistics were done using Statistical Package for the Social Sciences (SPSS) program (SPSS Inc., Version 20). All data were expressed as mean \pm Standard Error of Mean (SEM). Statistical significance for data was determined using a one-way analysis of variance (ANOVA) with post-hoc test, significance calculated by LSD (least significant difference). Correlation and lines of regression were calculated by linear regression analysis and the level of significance was accepted as $p<0.05$.

\section{Results}

\section{Changes in body weights and cardiac weights:}

By the end of the experiment, the final Body Weights (fBW) were insignificantly changed in the four studied groups. As regard absolute and relative cardiac weights, there was no significant difference among the four studied groups.

\section{Changes in ECG [Figs. (1-6) and plate]:}

Q-T interval, both observed (Q- $\left.\mathrm{T}_{\mathrm{o}}\right)$ and corrected $\left(\mathrm{Q}-\mathrm{T}_{\mathrm{c}}\right)$, showed significant prolongation in Dox and Exc + Dox groups compared to control group. Moreover, Exc + Dox group showed significant prolongation compared to Dox group. However, 
Exc group showed insignificant changes in Q-T interval compared to the control group. Dox alone didn't change the R voltage but in Exc + Dox group, $R$ voltage was significantly decreased compared to Dox group and compared to control group. The changes in the PR interval and QRS duration were insignificant.

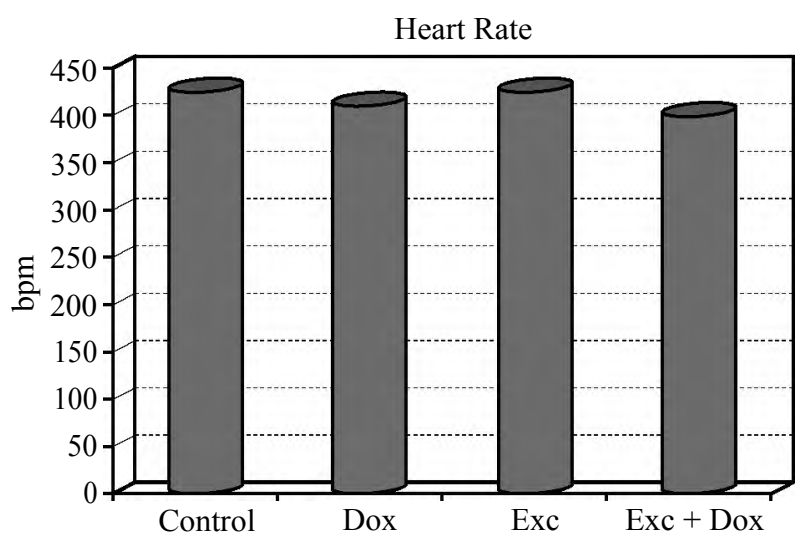

Fig. (1): Heart rate in different studied rat groups.

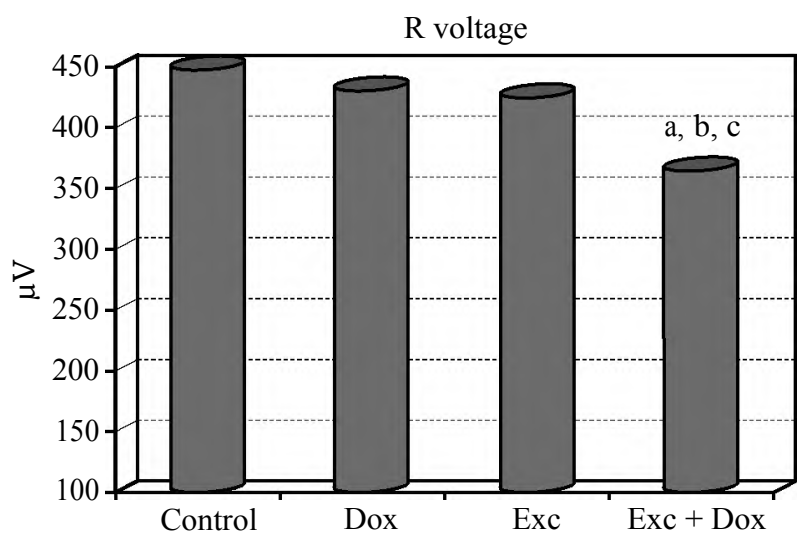

Fig. (2): R voltage in different studied rat groups.

$p$ : Significance of difference by 1 way ANOVA among the 4 studied groups:

a: Significant by LSD at $p<0.05$ from the control group.

b: Significant by LSD at $p<0.05$ from the Dox group.

c: Significant by LSD at $p<0.05$ from the Exc group.

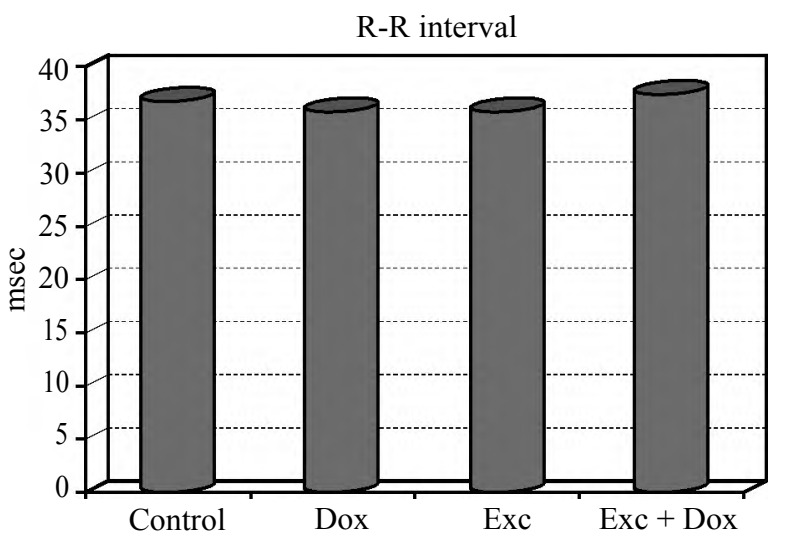

Fig. (3): P-R interval in different studied rat groups.

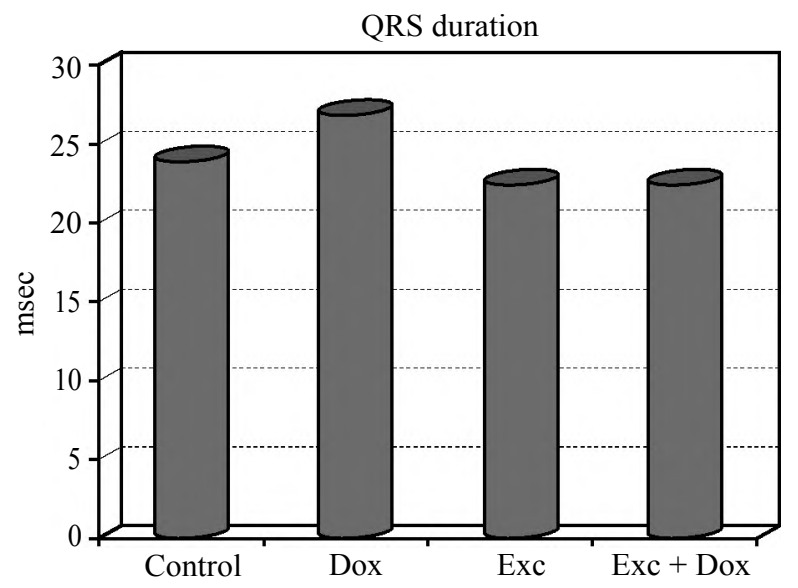

Fig. (4): QRS complex in different studied rat groups.

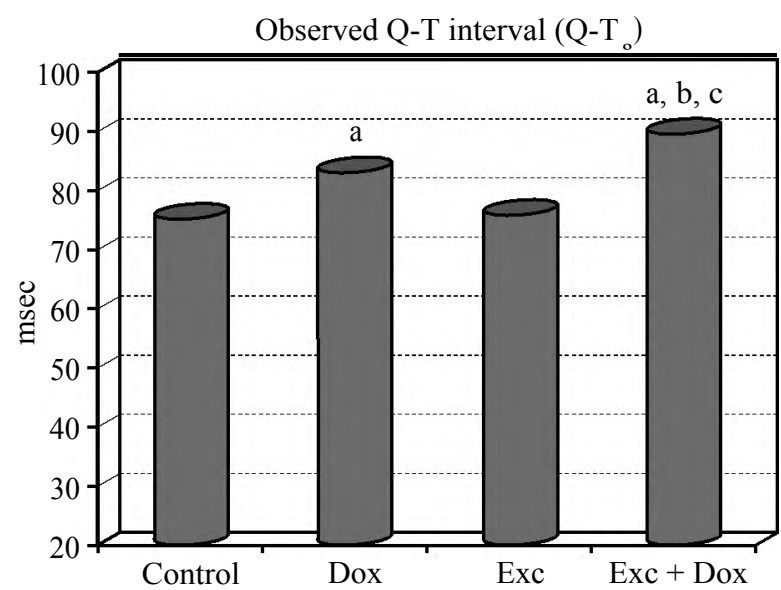

Fig. (5): QT- interval in different studied rat groups.

$p$ : Significance of difference by 1 way ANOVA among the 4 studied groups:

a: Significant by LSD at $p<0.05$ from the control group.

b: Significant by LSD at $p<0.05$ from the Dox group.

c: Significant by LSD at $p<0.05$ from the Exc group.

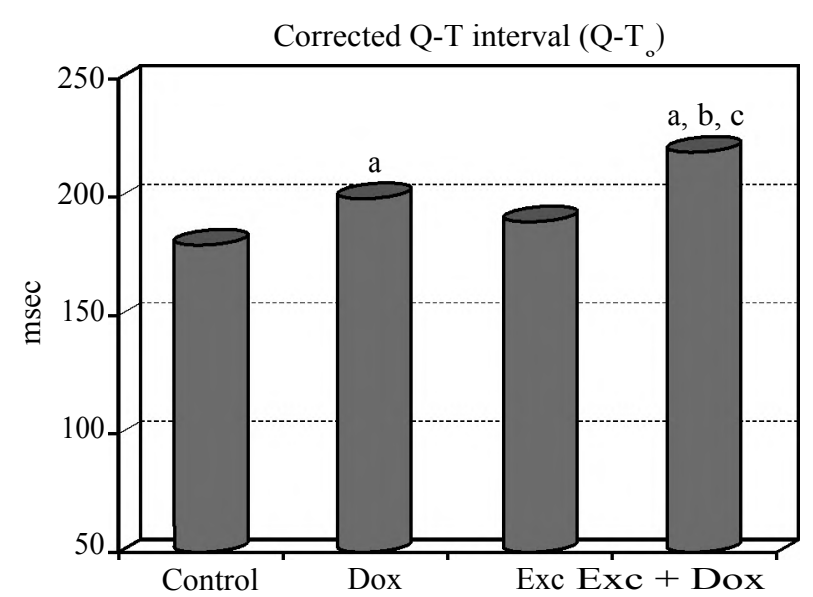

Fig. (6): QT-C in different studied rat groups.

$p$ : Significance of difference by 1 way ANOVA among the 4 studied groups:

a: Significant by LSD at $p<0.05$ from the control group.

b: Significant by LSD at $p<0.05$ from the Dox group.

c: Significant by LSD at $p<0.05$ from the Exc group. 
(A): Control:

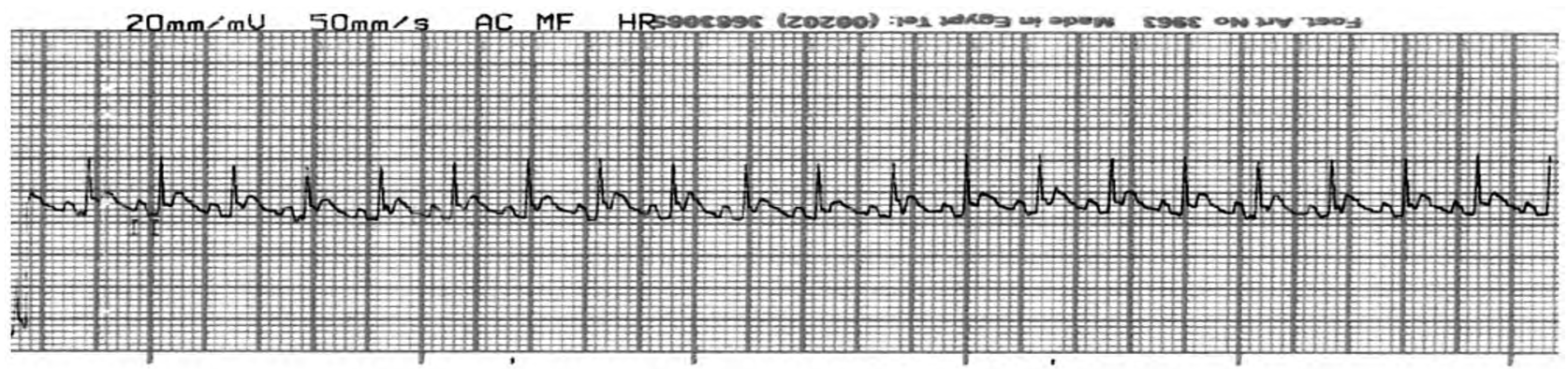

(D): Dox:

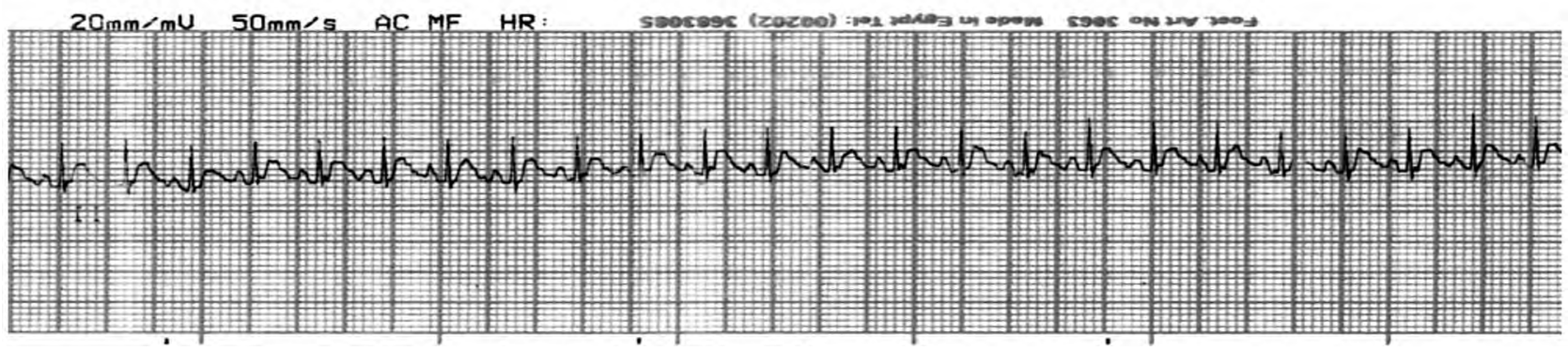

(B): Exc:

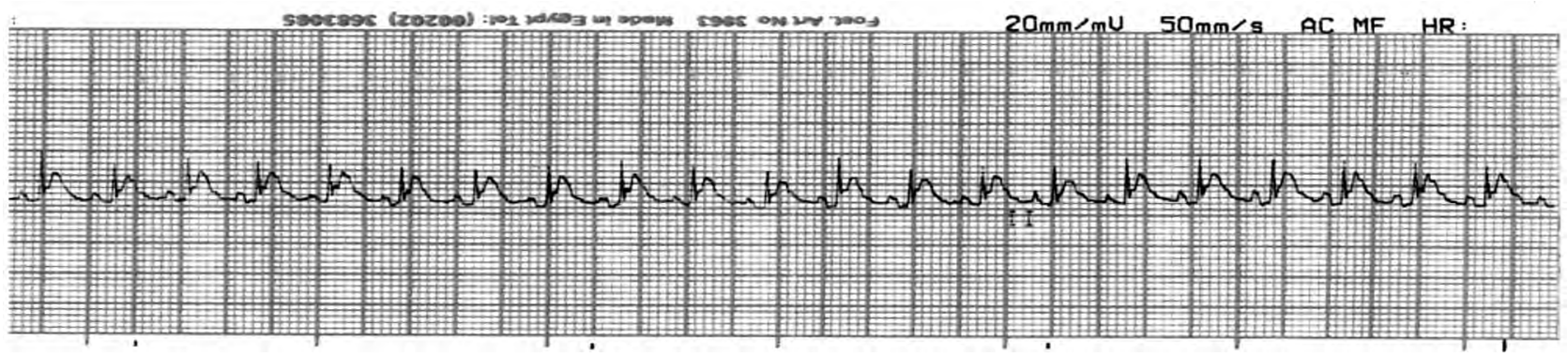

(C): $E x c+$ Dox:

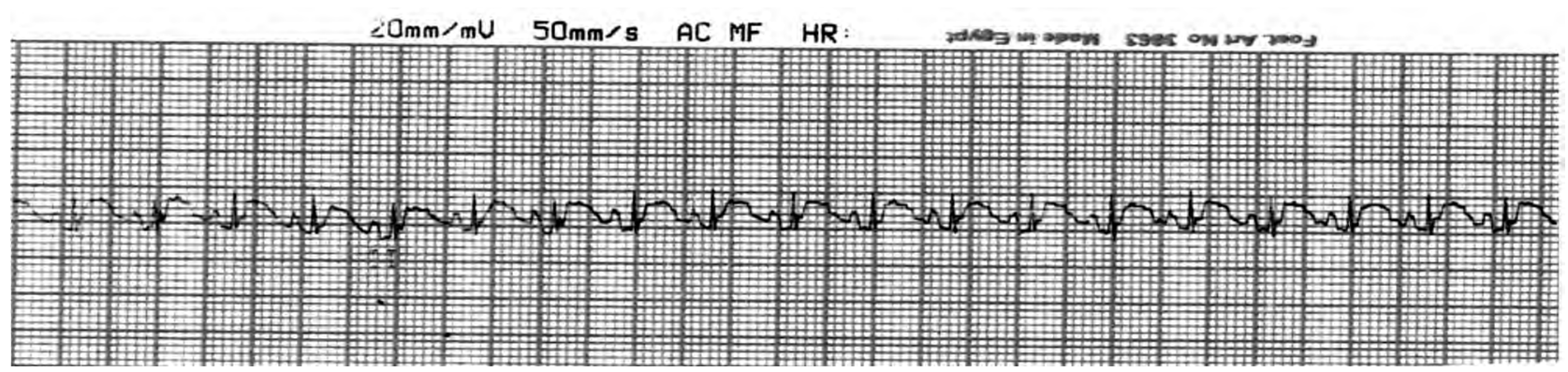

Plate of ECG: ECG record in the four different groups; control, Dox, Exc \& Exc + Dox groups.

Changes in arterial blood pressure Figs. (7-10):

Doxorubicin treatment resulted in insignificant increase in systolic (SBP), diastolic (DBP) and mean (MAP) arterial blood pressure that was asso- ciated with insignificant increase in the simultaneously recorded Heart Rate (sHR). However, when Dox treatment was preceeded by 3 days swim exercise training program (Exc + Dox group), the elevation in SBP, DBP and MAP became significant and the reduction in the sHR, also became significant. 


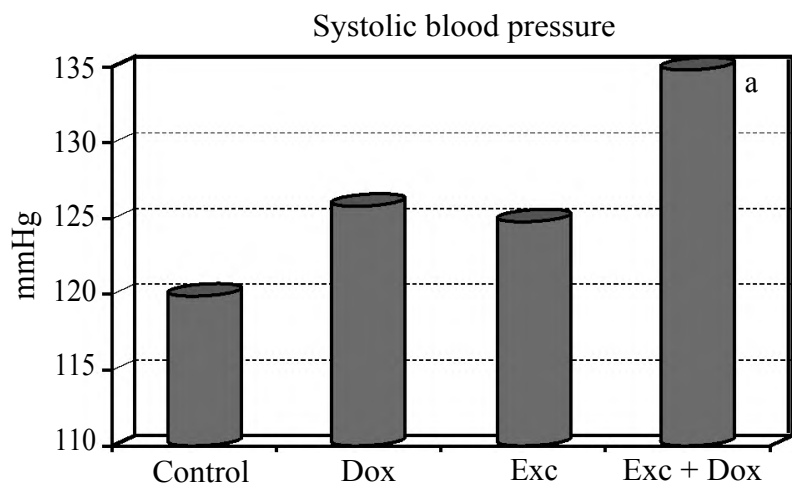

Fig. (7): Systolic Blood Pressure (SBP) in different studied rat groups.

$p$ : Significance of difference by 1 way ANOVA among the 4 studied groups:

a: Significant by LSD at $p>0.05$ from the control group.

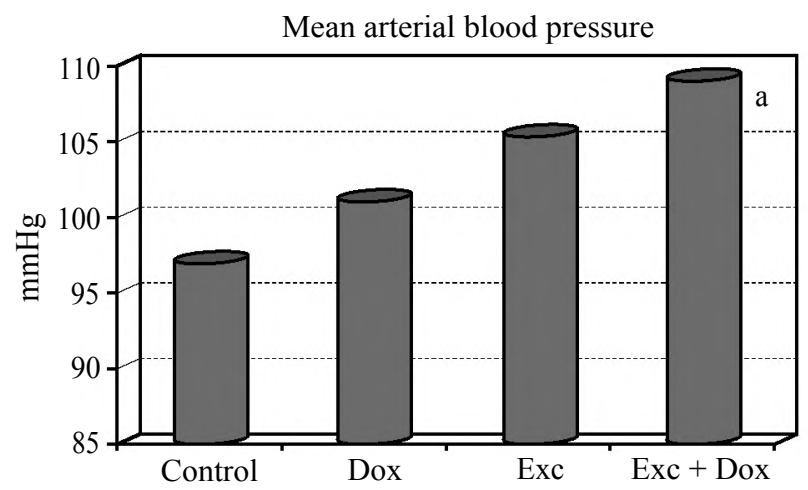

Fig. (9): Mean Arterial Pressure (MAP) in different studied rat groups.

$p$ : Significance of difference by 1 way ANOVA among the 4 studied groups:

a: Significant by LSD at $p<0.05$ from the control group.

Changes in biochemical parameters (Tables 1,2):

SGOT was significantly increased in Dox group and in Exc + Dox group compared to control group. However, cardiac troponin I (cTnI), Lactate Dehydrogenase (LDH) and Creatine Phosphokinase (CPK-MB) showed insignificant changes.

Regarding the cardiac muscle oxidative status, Malondialdehyde (MDA) was significantly increased in Dox group compared to control group. In Exc + Dox group, it was significantly decreased compared to Dox group. However, the changes in total antioxidant capacity were insignificant.

Concerning the cardiac tissue heat shock protein 20 (Hsp20), it was significantly increased in Dox group compared to control group, but significantly decreased in Exc + Dox group compared to Dox group. On the other hand, Exc group and Exc + Dox group were insignificantly changed compared to control group.

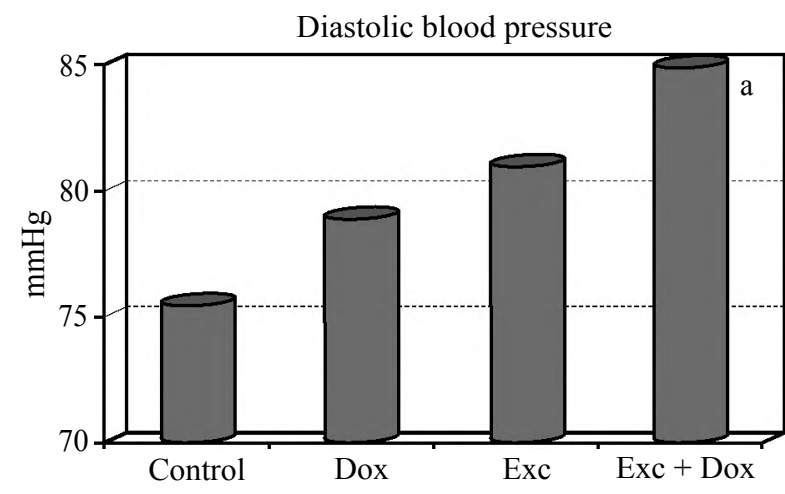

Fig. (8): Diastolic Blood Pressure (DBP) in different studied rat groups.

$p$ : Significance of difference by 1 way ANOVA among the 4 studied groups:

a: Significant by LSD at $p<0.05$ from the control group.

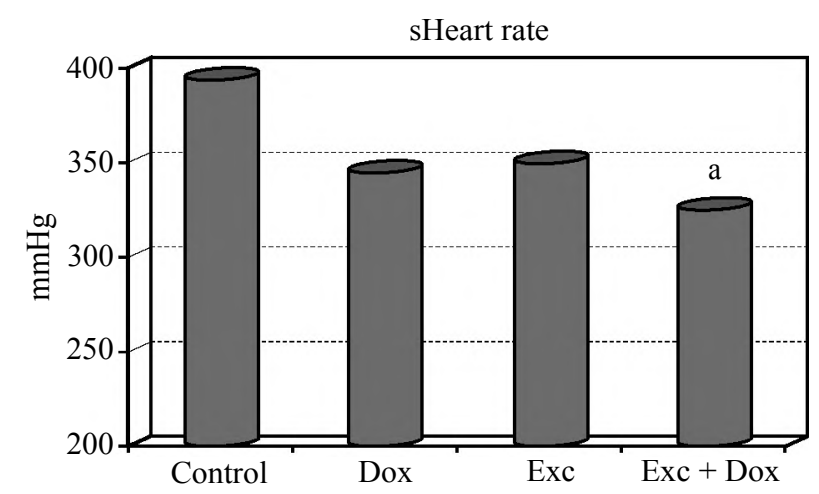

Fig. (10): Simultaneously recorded Heart Rate (sHR) in different studied rat groups.

$p$ : Significance of difference by 1 way ANOVA among the 4 studied groups:

a: Significant by LSD at $p<0.05$ from the control group.

Table (1): Mean values of serum glutamic oxaloacetic transaminase (SGOT, U/ml), cardiac troponin I (cTnI, $\mathrm{ng} / \mathrm{ml})$, lactate dehydrogenase (LDH, U/L) and creatine phosphokinase (CPK-MB, U/L) in control, doxorubicin-treated (Dox), swim-exercised (Exc) and swim-exercised doxorubicin-treated (Exc + Dox) rat groups.

\begin{tabular}{lllll}
\hline & Control & \multicolumn{1}{c}{ Dox } & \multicolumn{1}{c}{ Exc } & Exc + Dox \\
\hline SGOT & (14) $^{1}$ & & $(16)$ & $(12)$ \\
Mean \pm & 82.07 & $108.6 \mathrm{a}$ & 73.75 & $116.9 \mathrm{a}^{\prime} \mathrm{c}$ \\
SEM & \pm 7.08 & \pm 8.66 & \pm 8.19 & \pm 7.37 \\
cTnI & $(9)$ & $(11)$ & $(14)$ & $(10)$ \\
Mean \pm & 3.13 & 2.87 & 3.05 & 3.11 \\
SEM & \pm 0.52 & \pm 0.27 & \pm 0.30 & \pm 0.33 \\
LDH & $(8)$ & $(13)$ & $(10)$ & $(11)$ \\
Mean \pm & 2006.4 & 1547.1 & 1439.7 & 1585.7 \\
SEM & \pm 302.4 & \pm 133.2 & \pm 203.3 & \pm 217.2 \\
CPK-MB & $(9)$ & $(10)$ & $(13)$ & $(12)$ \\
Mean \pm & 729.3 & 525.9 & 545.8 & 587.4 \\
SEM & \pm 66.31 & \pm 92.62 & \pm 49.97 & \pm 75.39 \\
\hline
\end{tabular}

In parenthesis: Number of observations.

$p$ : Significance of difference by 1 way ANOVA among the 4 studied

groups:

b: Significant by LSD at $p<0.05$ from the Dox group.

c: Significant by LSD at $p<0.05$ from the Exc group. 
Table (2): Mean values of cardiac tissue malondialdehyde (MDA, pmol/g tissue), total antioxidant capacity (T.antioxidant, umol $/ \mathrm{g}$ ) and heat shock protein 20 (Hsp20, ng/g) in control, doxorubicin-treated (Dox), swim-exercised (Exc) and swim-exercised doxorubicin-treated (Exc + Dox) rat groups.

\begin{tabular}{lllll}
\hline & Control & Dox & Exc & Exc + Dox \\
\hline MDA & $(8)$ & $(11)$ & $(13)$ & $(10)$ \\
Mean & 3.78 & $9.91 \mathrm{a}$ & 4.92 & $4.80 \mathrm{~b}$ \\
\pm SEM & \pm 1.36 & \pm 2.33 & \pm 0.98 & \pm 0.92 \\
& & $(11)$ & $(14)$ & $(10)$ \\
T.antioxidant & $(9)$ & 18.61 & 19.35 & 16.06 \\
Mean & 20.68 & 18. & \pm 1.93 \\
\pm SEM & \pm 2.23 & \pm 2.61 & \pm 2.09 & $(10)$ \\
Hsp20 & $(9)$ & $(12)$ & $(11)$ & $(1)$ \\
Mean & 9.49 & $11.60 \mathrm{a}$ & 10.25 & $9.64 \mathrm{~b}$ \\
\pm SEM & \pm 0.54 & \pm 0.75 & \pm 0.78 & \pm 0.56 \\
\hline
\end{tabular}

In parenthesis: Number of observations.

$p$ : Significance of difference by 1 way ANOVA among the 4 studied groups:

a: Significant by LSD at $p<0.05$ from the control group.

b: Significant by LSD at $p<0.05$ from the Dox group.

c: Significant by LSD at $p<0.05$ from the Exc group.

\section{Changes in Echo Fig. $(11 A, B)$ :}

Ejection fraction (EF \%) and fraction of shortening (FS \%) were significantly decreased in Exc + Dox group compared to Dox group.

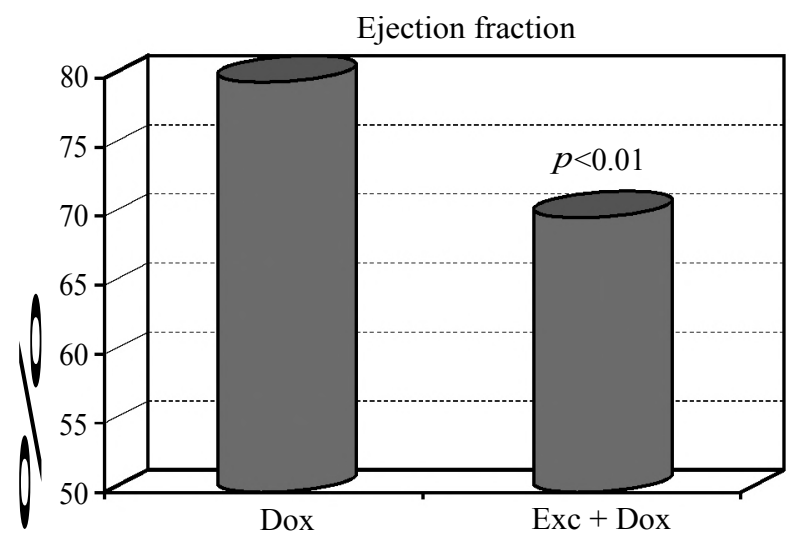

(A)

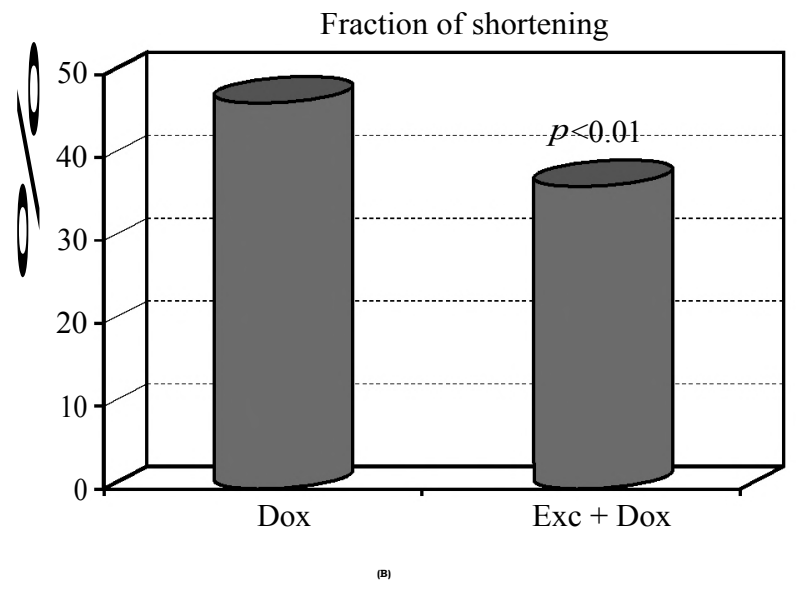

Fig. (11): Ejection fraction (A) and fraction of shortening (B) in Dox and Exc + Dox rat groups.

\section{Correlation studies Figs. (12-20):}

SGOT was positively correlated with left ventricular/body weight. Also, it was positively correlated with systolic and mean blood pressure. In addition, it was positively correlated with QTand QT $-_{\mathrm{c}}$. On the other hand, SGOT was negatively correlated with total antioxidant capacity. HR was positively correlated with $\mathrm{EF} \%$ and $\mathrm{FS} \%$. In addition, QT- ${ }_{0}$ was positively correlated with SBP.

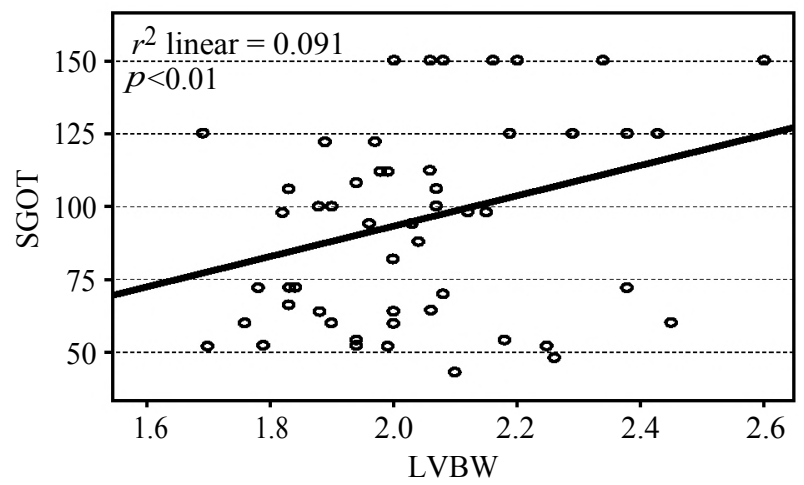

Fig. (12): Regression lines and coefficients of determination $(r)$ between Serum Glutamic-Oxaloacetic Transaminase (SGOT) and Left Ventricular/Body Weight (LV/BW).

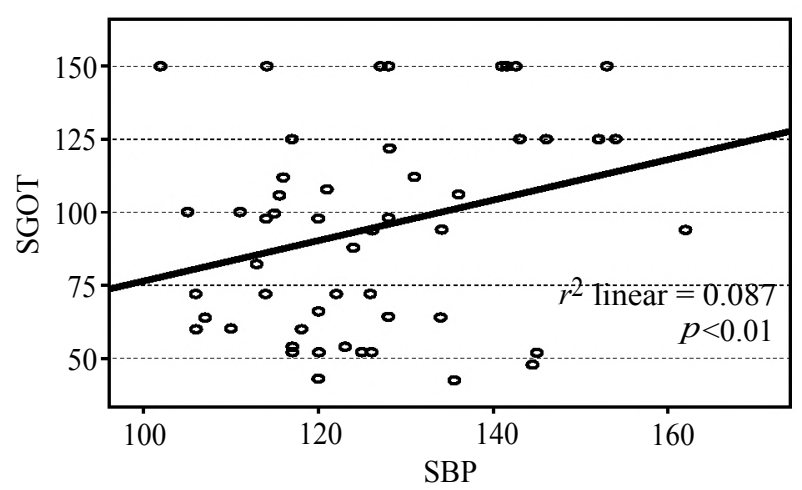

Fig. (13): Ręgression lines and coefficients of determination $(r)$ between Serum Glutamic-Oxaloacetic Transaminase (SGOT) and Systolic Blood Pressure (SBP).

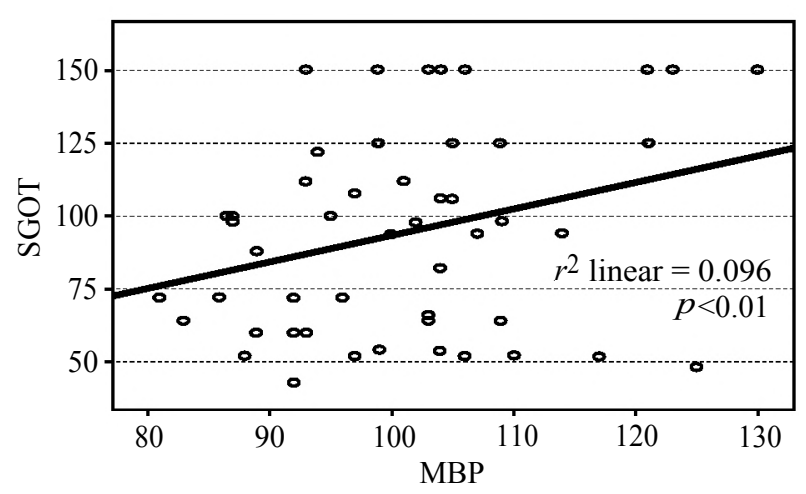

Fig. (14): Ręgression lines and coefficients of determination $(r)$ between Serum Glutamic-Oxaloacetic Transaminase (SGOT) and Mean Arterial Blood Pressure (MBP). 


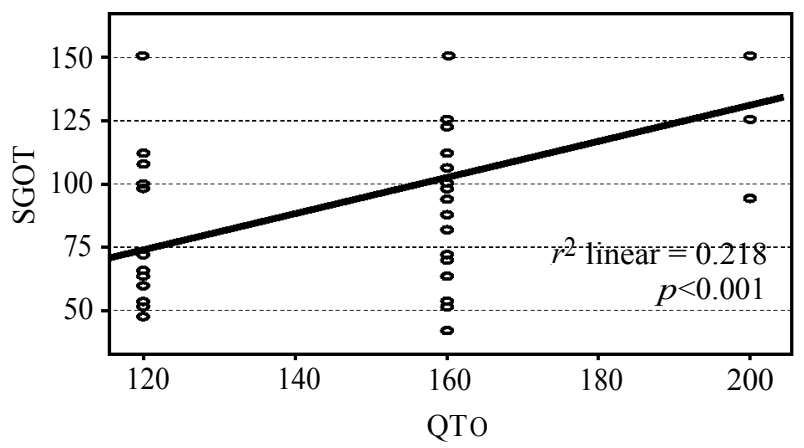

Fig. (15): Regression lines and coefficients of determination $(r)$ between Serum Glutamic-Oxaloacetic Transaminase (SGOT) and observed QT (Q-T O).

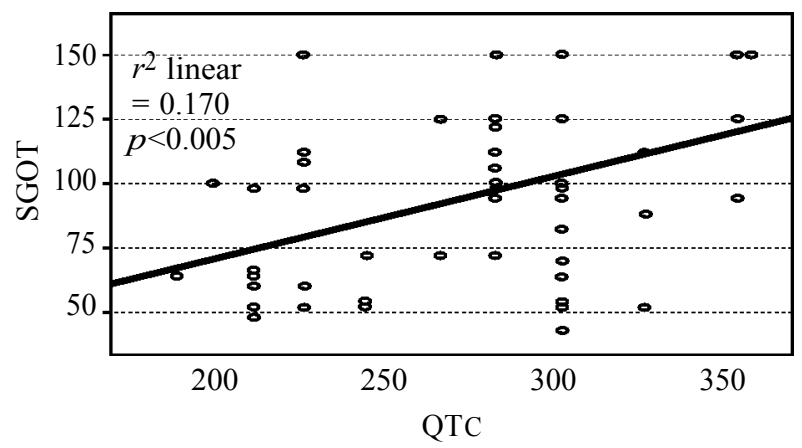

Fig. (16): Regression lines and coefficients of determination $(r)$ between Serum Glutamic-Oxaloacetic Transaminase (SGOT) and corrected QT (Q-TC).

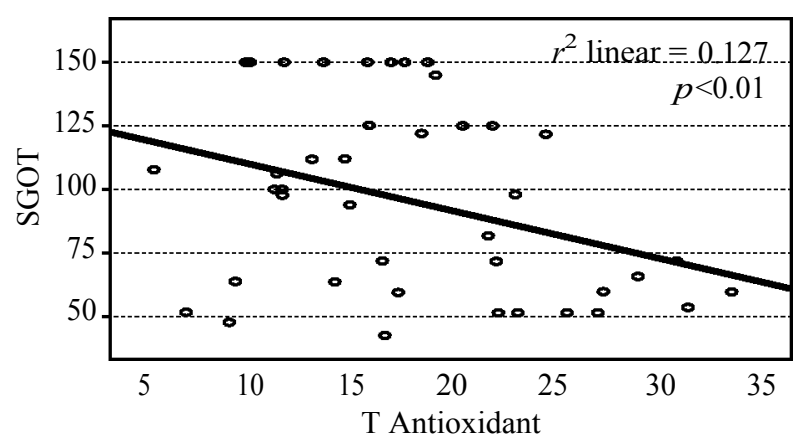

Fig. (17): Regression lines and coefficients of determination $(r)$ between Serum Glutamic-Oxaloacetic Transaminase (SGOT) and Total Antioxidant capacity (T. Antioxidant).

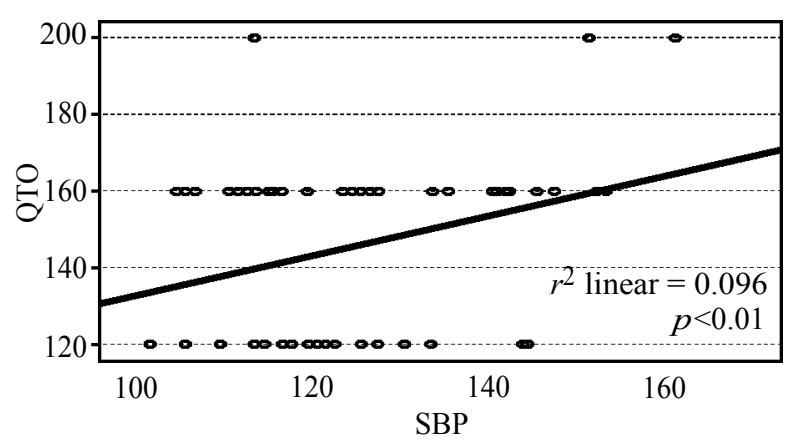

Fig. (18): Regression lines and coefficients of determination $(r)$ between observed QT (Q-TO) and Systolic Blood Pressure (SBP).

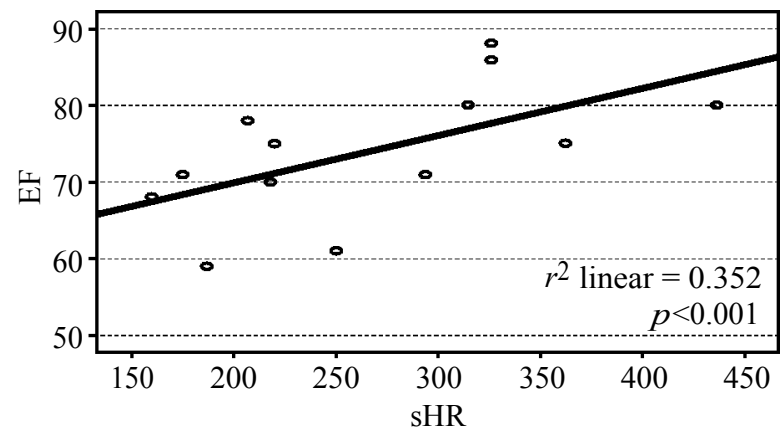

Fig. (19): Regression lines and coefficients of determination $(r)$ between Ejection Fraction (EF) and simultaneously recorded Heart Rate (sHR).

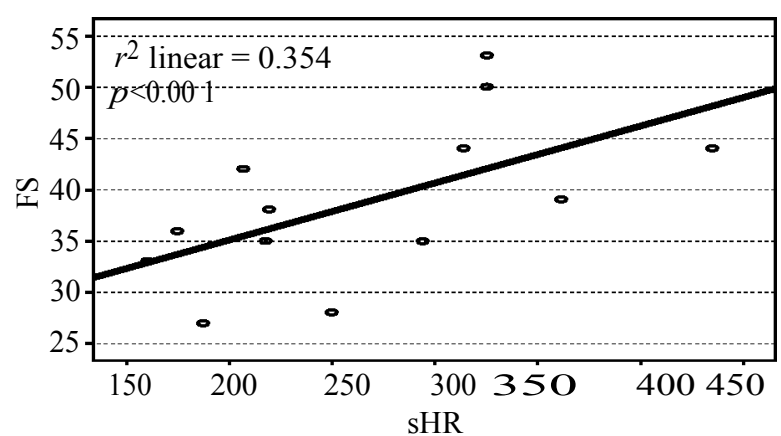

Fig. (20): Regression lines and coefficients of determination $(r)$ between Fraction of Shortening (FS) and simultaneously recorded Heart Rate (sHR).

\section{Discussion}

Effect on ECG: The prolonged Q-Tc with Dox treatment recorded in this study was in agreement with previous reports of many authors [23-25]. They reported that Q-T prolongation and arrhythemias were often observed during 24 hours initiation of Dox treatment. Doxorubicin prolonged the action potential duration in isolated myocytes and papillary muscles and blocked the delayed rectifier potassium current in guinea-pig [26] and in rabbits [27]. Also, Newton et al., [28] reported that the malfunction of the ion channels leads to an intracellular excess of the positively charged ions that extends ventricular repolarization and results in Q-T prolongation which could be a marker for potential ventricular tachyarrythemia and may be a risk factor for sudden death [29].

Application of 3 days swim exercise training program, just before Dox treatment, resulted in further prolongation of the $\mathrm{Q}-\mathrm{T}_{\mathrm{o}}$ and the $\mathrm{Q}-\mathrm{T}_{\mathrm{c}}$ intervals and both became even more prolonged than that with Dox treatment alone. These findinga points to the increased hazards of the pro-arrhythmogenic effect of Dox administration if it is combined with short-term exercise training. These findings could be attributed to the enhancement or 
increased activation of L-type calcium channels that put on top of the prolonged Q-T induced by Dox treatment. Consequently, short-term exercise training program just before Dox treatment become a risk factor that increases the proarrhythmogenic effect of Dox.

Regarding $\mathrm{R}$ wave voltage, it was insignificantly lower in Dox treatment group and in the exercising group but when exercise training is shortly combined with doxorubicin treatment (Exc + Dox group), the depression of the $\mathrm{R}$ wave voltage become severe and it was significantly lower than that of the control, Dox-treated and exercise groups. Our findings are in agreement with the work of Anadolu [30] who reported that doxorubicin injection in female rats resulted in significantly depressed $\mathrm{R}$ wave voltage. In a previous study done by Diab [9], Dox perfusion of isolated rat hearts induced marked deterioration in cardiac functions proved by significant bradycardia, prolongation of all cardiac times with reduction of the myocardial flow rate. This damage was confirmed by ultrastructure examination with electron microscopy that revealed myofilament disarray with areas of focal loss and necrosis rarefied matrix of the mitochondria signifying its degeneration.

Effect on blood pressure and heart rate: In the present study, when single dose of doxorubicin treatment $(20 \mathrm{mg} / \mathrm{kg}$ body weight $)$ was preceded by 3 days swim exercise training program $(\mathrm{Exc}+$ Dox) group, the elevation in SBP, DBP and MAP became significant and the reduction in the sHR, also became significant. Ivanova et al., [31] and Hirai et al., [32] noticed elevation in SBP after different periods of Dox treatment, and they attributed this elevation to increased plasma matrix metalloproteinase activities and impaired nitric oxide production in the kidney. Dox-induced changes in blood pressure could be explained by its interaction with the autonomic nervous system with increase in the efficiency of the sympathetic part and reduction of the activity of the parasympathetic part [33] or by an increased plasma renin activity leading to sodium and water retention [34] In contrast, other long term studies reported that Dox treatment induced lowering of arterial blood pressure [35].

Changes in heart rate could be explained by the Dox-induced suppression of cholinesterase synthesis in the heart muscle with a subsequent increase in acetylcholine activity [33].

It worth noting that the SGOT-marker of cardiac muscle injury-was positively correlated with SBP,
MAP and Q-T interval. The change in these parameters; the significant elevation in SBP and MAP and the significant prolongation in Q-T interval established in the Exc + Dox group, represent exercise insult on the cardiovascular system with Dox treatment.

Biochemical effects in serum: In the present study, Dox induced significant increase in SGOT indicating cardiac muscle damage and loss of cardiomyocyte membrane integrity. This increase was also observed in Exc + Dox group indicating that Exc didn't alleviate the damage induced by doxorubicin. SGOT was positively correlated with left ventricular/body weight ratio and these points to the left ventricle as the source for this elevation in SGOT in the present study.

This result was in line with Divakaran and Nair [36] who showed that Dox injection at a dose of $25 \mathrm{mg} / \mathrm{kg}$ resulted in increase in SGOT level and the increase in LDH and CPK level occurred in late cardiac injury especially during clinical followup of doxorubicin therapy.

In contrast to our results, Ascensao et al., [37] reported that single dose of Doxinjection $20 \mathrm{mg} / \mathrm{kg}$ induced a significant increase in plasma levels of cTnI which reflects enhanced cTnI release from the heart. However, chronic endurance training (14wk of endurance treadmill running, 60-90min/ day) resulted in a significant reversal of Doxinduced cardiotoxicity which is not the case in the current study as short-term exercise was not effective to reverse the cardiac damage induced by doxorubicin. Also, the non significant change in $\mathrm{LDH}, \mathrm{CPK}-\mathrm{MB}$ and cTnI may be due to injection of a single dose of doxorubicin that was not sufficient to increase those cardiac markers as they depends on the total cumulative dose of doxorubicin [38,39]

Biochemical results from cardiac tissues showed significant increase in MDA and Hsp20 in Dox group that was reversed by exercise. The increase in Hsp20 with doxorubicin may indicate that it is increased to alleviate the damage induced by doxorubicin injection. In the present work, Dox, in a dose of $20 \mathrm{mg} / \mathrm{kg}$, increased MDA but did not affect total antioxidant capacity. Ascensao et al., [37] found that Dox treatment in the same dose significantly increased the level of MDA from heart mitochondrial extracts but was not sufficient to significantly alter any of the measured antioxidant enzymes. Harris and Starnes [40] showed that superoxide dismutase (one of the antioxidant enzymes) was not changed in a Dox-treated group. 
On the other hands, Kanter et al., [41] showed that Dox decreased Glutathione Peroxidase (GPX) and prevented the exercise induced induction of GPX. However, this study used chronic Dox treatment protocols.

Therefore, the present study demonstrated that single dose of Dox was sufficient to increase MDA in cardiac tissue but still insufficient to alter the total antioxidant capacity of the heart.

It is worth noting that, short-term (3 days) swim exercise didn't increase antioxidant enzymes. However, exercise for longer periods (5 days/week for 2 weeks) was found to increase GPX in cardiac tissue [42]. Likewise, Chicco et al., [12] found that voluntary exercise by wheel running for 8 weeks induced protection against the cardiac dysfunction induced by acute Dox exposure. This functional cardioprotection was associated with attenuation of Dox-induced lipid peroxidation in the heart. Also, SOD and catalase were elevated following endurance exercise training [13,37]. Therefore, 3 days swim exercise in the present work was not sufficient to obtain the expected protective benefits of exercise against doxorubicin.

Effect on Echo: The data obtained from echocardiography showed that there was significant decrease in ejection fraction and in fraction of shortening in exercised group treated with Dox compared to the Dox group. The reduction of the EF\% and FS\% (parameteres of left ventricular systolic function) indicates that short-term exercise training did not protect or improve left ventricular function but even worsened it. These findings are opposing to previous observations that Dox treatment could cause significant impairment of left ventricular systolic function that was returned back to normal by 2 weeks exercise training [12,39].

\section{Conclusion:}

Short-term swim exercise training just prior to doxorubicin exposure is risky and makes the heart more predisposed to arrhythmia despite of the relative improvement in cardiac oxidative status.

Limitation: For technical difficulties, the Echo was done only for a limited number of rats. Therefore, the results expressed for echo were statistically analyzed comparing (Dox) and (Exc + Dox) groups.

Competing interests: The authors declare that no competing interests or grants exist.

Author contributions: The experiments were performed in our laboratory in the Physiology
Department, Faculty of Medicine, Ain-Shams University, Cairo, Egypt.

Faten M.A. Diab, design of the work; interpretation of data; revising critically for important intellectual content. Ramadan. A. Saad, design of the work; participated in the practical part; drafting the work and revising it. Noha A. H. Nassef, design of the work; interpretation of data; participated in the practical part; drafting the work and revising it critically for important intellectual content. Christina M. Wadie, conduct the practical part; acquisition of data for the work; drafting the work. All authors approved the final version of the manuscript and agreed to be accountable for all aspects of the work in ensuring that questions related to the accuracy or integrity of any part of the work are appropriately investigated and resolved; and that all persons designated as authors qualify for authorship, and all those who qualify for authorship are listed.

Funding: The authors declare that no funds exist.

Acknowledgement: The authors acknowledge the courtesy of the Pediatric Department, Faculty of Medicine, Ain Shams University for helping in echocardiography).

\section{References}

1- CORTES-FUNES H. and CORONADO C.: Role of anthracyclines in the era of targeted therapy. Cardiovasc. Toxicol.; 7: 56-60, 2007.

2- SINGAL P.K. and ILISKOVIC N.: Doxorubicin-induced cardiomyopathy. N. Engl. J. Med.; 339: 900-5, 1998.

3- WALLACE K.B.: Doxorubicin-induced cardiac mitochondrionopathy. Pharmacol. Toxicol.; 93: 105-15, 2003.

4- SIVESKI-ILISKOVIC N., HILL M., CHOW D.A. and SINGAL P.K.: Probucolprotects against adriamycin cardiomyopathy without interfering with its antitumor effect. Circ.; 91: 10-15, 1995.

5- MUKHERJEE S., BANERJEE S.K., MAULIK M., DINDA A.K., TALWAR K.K. and MAULIK S.K.: Protection against acute adriamycin-induced cardiotoxicity by garlic: Role of endogenous antioxidant and inhibition of TNFalpha expression. B.M.C. Phamacol.; 3 (16): 1471-2210, 2003.

6- CHAMBERS J.T., CHAMBERS S.K., KOHORN E.I., CARCANGIU M.L. and SCHWARTZ P.E.: Uterine papillary serous carcinoma treated intrapritoneal cisplatin and intravenous doxorubicin and cyclophosphamide. Gynecol. Oncol.; 60 (3): 438-42, 1996.

7- FENG S.S. and CHEN S.: Chemotherapeutic engineering: Application and further development of chemical engineering particles for chemotherapy of cancer and other diseases. Chem. Eng. Sci.; 58 (18): 4087-114, 2003. 
8- ABRAHAM S.A., WATERHOUSE D.N. and MAYER L.D.: The liposomal formulation of doxorubicin. Methods Enzymol.; 391: 71-97, 2005.

9- DIAB F.M.: Physiological studies on the protective effect of melatonin against doxorubicin cardiotoxicity. Egypt J. Med. Lab. Sci.; 17 (1): 1-10, 2008.

10- AWAD H.H.: Potential Cardioprotective Effects of Vitamin D on Cardiotoxicity induced by Doxorubicin. (Master thesis). Faculty of Pharmacy, Ain Shams University, 2015.

11-HYDOCK D.S., LEIN C.Y., JENSEN B.T., SCHNEIDER C.M. and HAYWARD R.: Exercise preconditioning provides long-term protection against early chronic doxorubicin cardiotoxicity. Integr. Cancer Ther.; 10 (1): 47-57, 2011.

12- CHICCO A.J., SCHNEIDER C.M. and HAYWARD R.: Voluntary exercise protects against acute doxorubicin cardiotoxicity in the isolated perfused rat heart. Am. J. Physiol. Regul. Integr. Comp. Physiol.; 289 (2): R424R431, 2005.

13- KAVAZIS A.N., SMUDER A.J., MIN K., TÜMER N. and POWERS S.K.: Short term exercise training protects against doxorubicin-induced cardiac mitochondrial damage independent of HSP72. Am. J. Physiol. Heart Circ. Physiol.; 299: H15 15-H1524, 2010.

14- STEIN A.B.1., TIWARI S., THOMAS P., HUNT G., LEVENT C., STODDARD M.F., TANG X.L., BOLLI R. and DAWN B.: Effects of anesthesia on echocardiographic assessment of left ventricular structure and function in rats. Basic. Res. Cardiol.; 102 (1): 28-41, 2007.

15- SAHN A.: Determination of pulmonary to systemic blood flow ratio in children by simplified Doppler echocardiographic method. J. Am. Coll Cardiol.; 1: 825-30, 1989.

16- GOLDSCHLAGER N. and GOLDMAN M.J.: Electrocardiography: Essentials of interpretation. Ch. 3, Pp. 13-8. Middle East Edition, Lang Medical Publications, Los Anglos, California, 1984.

17- OHKAWA H., OHISHI W. and ANAL Y.K.: Assay for lipid peroxides in animal tissues by thiobarbituric acid reaction. Anal. Biochem.; 95: 351-8, 1979.

18- KORACEVIC D., KORACEVIC G., DJORDJEVIC V., ANDREJEVIC S. and COSIC V.: Method for the measurement of antioxidant activity in human fluids. J. Clin. Pathol.; 54: 356-61, 2001.

19- REITMAN A. and FRANKEL S.: A colorimetric method for the determination of serum glutamic oxalacetic and glutamic pyruvic transaminases. Am. J. Clin. Pathol.; 28 (1): 56-63, 1957.

20- APPLE FRED S., CHRISTENSON R.H., VALDES R.J., ANDRIAK A.B., DUH SHOW-HONG, FENG Y.J., SAEED A.J., JOHNSON NANCY J., KOPLEN BRENDA, MASCOTTI K. and WU ALAN J.: Simultaneous rapid measurement of whole blood myoglobin, creatine kinase $\mathrm{MB}$ and cardiac troponin I by the triage cardiac panel for detection of myocardial infarction. Clin. Chem.; 45: 199-205, 1999.

21- BULH S.N. and JACKSON K.Y.: Kinetic method for the determination of serum LDH. Clin. Chem.; 24: 828-32, 1978.

22- THOLEN D.W., LINNET K., KONDRATOVICH M., ARMBRUSTER D.A., GARRETT P.E., JONES R.L., et al.: Protocols for determination of limits of detection and limits of quantitation; approved guideline. NCCLS Document EP 17 A. NCCLS, Pennsylvania, USA, 2004.

23- STEINBERG J.S., COHEN A.J., WASSERMAN A.G., COHEN P. and ROSS AM.: Acute arrhythmogenicity of doxorubicin administration. Cancer; 60: 1213-8, 1987.

24- NOUSIAINEN T., VANNINEN E., RANTALA A., JANTUNEN E. and HARTIKAINEN J.: QT dispersion and late potentials during doxorubicin therapy for nonHodgkin's lymphoma. J. Intern. Med.; 245: 359-64, 1999.

25- DUCROQ J., MOHA H., OU MAATI, GUILBOT S., DILLY S., LAEMMEL E., PONS-HIMBERT C., FAIVRE J.F., BOIS P., STÜCKER O. and Le GRAND M.: Dexrazoxane protects the heart from acute doxorubicin-induced QT prolongation: A key role for IKS. B.J.P.; 159: 93-101, 2010.

26- WANG G.X., WANG Y.X., ZHOU X.B. and KORTH M.: Effects of doxorubicinol on excitation-contraction coupling in guinea pig ventricular myocytes. Eur. J. Pharmacol.; 423: 99-107, 2001.

27- MELBERG P., FLEISCHER D., STYPMANN J., OSADA N., MÖNNING G., ENGELEN M.A., et al.: Reduced repolarization reserve due to anthracycline therapy facilitates torsade de pointes induced by IKr blockers. Basic Res. Cardiol.; 102: 42-51, 2007.

28- NEWTON C.C., GUO C.Y., LARSON M.G., et al.: Common genetic variation in $\mathrm{KCNH} 2$ is associated with QT interval duration. Circ.; 116: 1128-36, 2007.

29- MORITA H., JIASHIN W.U. and DOUGLAS P. ZIPES: The QT syndromes: Long and short. Lancet; 372: 75063, 2008.

30- ANADOLU K.D.: Protective effect of carnosine on adriamycin-induced oxidative heart damage in rats. Epub.; 11 (1): 3-10, 2011.

31- IVANOVA M., DOVINOVA I., OKRUHLICOVA L., TRIBULOVA N., SIMONCIKOVA P., BARTEKOVA M., VLKOVICOVA J. and BARANCIK M.: Chronic cardiotoxicity of doxorubicin involves activation of myocardial and circulating matrix metalloproteinasesin rats. Acta. Pharmacol. Sin.; 33: 459-69, 2012.

32- HIRAI T., OKUMORA K., NISHIMOTO Y., SHUMIYA T., MURAKAMI R., TAKAHASHI R., ASAI T., MURAKAMI H., NUMAGUCHI Y., MATSUI H. and TOYOAKI: Upregulation of renal eNOS by high-sodium diet facilitates hypertension in doxorubicin-treated rats through enhanced oxidative stress. Toxicol.; 225 (2-3): 81-9, 2006.

33- GERSL V., BAJGAR J., KRS O., HRDINA R., PALICA V. and MAZUROVA Y.: Changes in cholinesterase activities after daunorubicin administration to rabbits. Hum. Exp. Toxicol.; 15: 834-8, 1996.

34- RASHIKH A., PILLAI K.K., AHMED S.J., AKHTAR M. and NAJMI A.K.: Aliskiren alleviates doxorubicininduced nephrotoxicity by inhibiting oxidative stress and podocyte injury. J. Renin-Angiotensin-Aldosteron Syst.; 14 (1): 14-22, 2013.

35- NOVAKOVA Z., STASTNA J., HONZIKOVA K., HRSTKOVA H., HONZIKOVA N., ZAVODNA A., FISER B. and HONZIK P.: Anthracycline Therapy and 24Hour Blood-Pressure Profile in Long-Term Survivors of Childhood Cancer. Physiol. Res.; 59 (Suppl. 1): S97S 102, 2010 . 
36- DIVAKARAN S.A. and NAIR C.K.K.: Amelioration of Doxorubicin Induced Cardiotoxicity in Tumor Bearing Mice by Ferulic Acid: A Mechanistic Study at Cellular and Biochemical Level. INT J. Tumor. Ther.; 1 (2): 6-13, 2012.

37- ASCENSAO A., MAGALHAES J., SOARES J.M., FERREIRA R., NEUPARTH M.J., MARQUES F., OLIVEIRA P.J. and DUARTE J.A.: Moderate endurance training prevents doxorubicin-induced in vivo mitochondriopathy and reduces the development of cardiac apoptosis. Am. J. Physiol. Heart Circ. Physiol.; 289: H722-H773, 2005.

38- EUGENE H.H., ZHANG J., STEVEN E., RIFAI N., CHADWICK D., TAKEDA K., YU Z.X. and VICTOR J.: Correlation Between Serum Levels of Cardiac Troponin-T and the Severity of the Chronic Cardiomyopathy Induced by Doxorubicin. J. Clin. Oncol.; 17: 2237-43, 1999.
39- ZHANG Y.W., SHI J., LI Y.J. and WEI L.: Cardiomyocyte death in doxorubicin-induced cardiotoxicity. Arc. Immunol. Ther. Exper.; 57 (6): 435-45, 2009.

40- HARRIS M.B. and STARNES J.W.: Effects of body temperature during exercise training on myocardial adaptations. Am. J. Physiol. Heart Circ. Physiol.; 280: H2271H2280, 2001.

41- KANTER M.M., HAMLIN R.L., UNVERFERTH D.V., DAVIS H.W. and MEROLA A.J.: Effect of exercise training on antioxidant enzymes and cardiotoxicity of doxorubicin. J. Appl. Physiol.; 59: 1298-303, 1985.

42- CHICCO A.J., HYDOCK D.S., SCHNEIDER C.M. and HAYWARD R.: Low-intensity exercise training during doxorubicin treatment protects against cardiotoxicity. J. Appl. Physiol.; 100: 519-27, 2006.

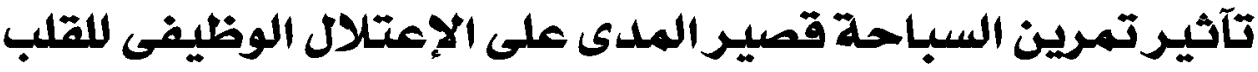

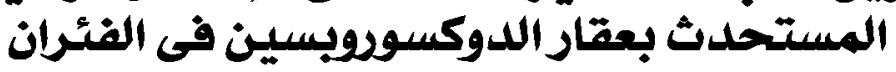

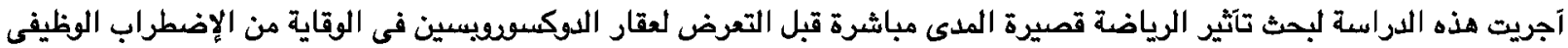

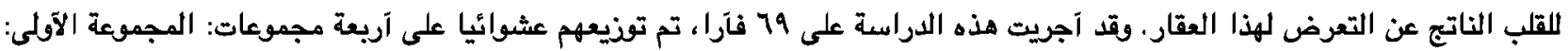

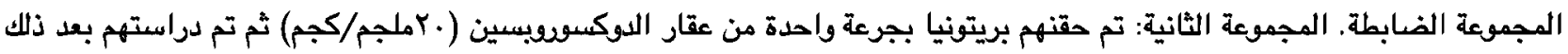
ب عץ ساعة. المجموعة الثالثة: تعرضت الفئران التمرين الرياضيى في صودة سباحة قصيرة المدى (ساعة يوميا لمدة ب آيام). المجموعة الرابعة: تعرضت لتمرين السباحة قصير المدى ثم تم حقنهم بريتونا بجرعة واحدة من عقار الدوكسوريسينين.

ويمكن تلخيص نتائج الدراسلة فيما يلى : بالمقارنة بالمجموعة الضابطة، فإن مجموعة الفئران التى تم حقنها بعقار الدوكسوروبسين آظهرت

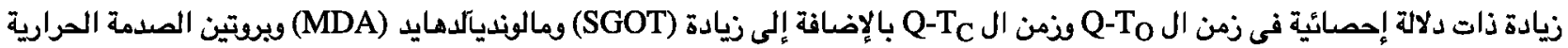

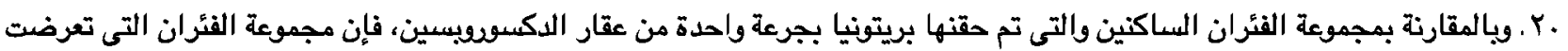

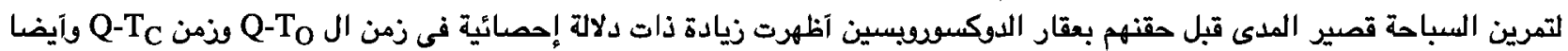

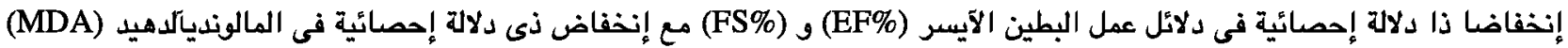

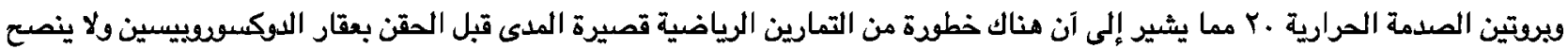

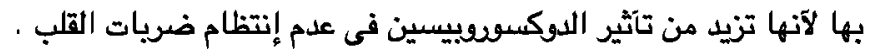

